\title{
TINGKAT PEMAHAMAN PELAKSANAAN PEKERJAAN KONTRUKSI PRESERVASI JALAN BERBASIS KONTRAK LONG SEGMENT PADA BALAI BESAR PELAKSANAAN JALAN NASIONAL VIII SURABAYA
}

\author{
Mochammad Faisol Akbar Khaqiqi ${ }^{1}$, Diah Ayu Restuti Wulandari ${ }^{2}$ \\ ${ }^{I}$ Prodi Teknik Sipil, Universitas Narotama, faisal949868@gmail.com \\ ${ }^{2}$ Prodi Teknik Sipil, Universitas Narotama, dee.ayu86@gmail.com
}

\begin{abstract}
ABSTRAK
Penerapan kontrak berbasis long segment yang dinilai baru untuk penguna jasa dan kontraktor di Balai Besar Pelaksanaan Jalan Nasional VIII. Sehingga di butuhkan pemahaman mengenai sistem tersebut. Para pihak mengalami kesulitan untuk menerapkan standar - standar yang sudah di tentukan serta pemahaman lingkup pekerjaan yang dilaksanakan, sehingga menyebabkan pelaksanaan pekerjaan berbasis long segment tidak efektif terlaksana dengan baik hingga saat ini.

Melihat permasalahan di atas maka, Penelitian ini dilakukan untuk mengidentifikasi faktor - faktor pemahaman dari pihak - pihak penguna jasa dan kontraktor dalam pelaksanaan preservasi jalan berbasis kontrak Long Segment pada Balai Besar Pelaksanaan Jalan Nasional VIII Surabaya, sehingga dapat diketahui faktor - faktor pemahaman penguna jasa dan kontraktor. Diharapakan penelitian ini berguna untuk menunjang pelaksanaan pekerjaan Long Segment kedepan bisa lebih efektif dalam pelaksanaanya. Metode yang digunakan dalam penelitian ini menggunakan Analytical Hirarchy Process (AHP).Sesuai dengan batasan penelitian ini, jumlah responden yang di gunakan yaitu 15 penguna jasa dan 15 penyedia jasa pada Balai Besar Pelaksanaan Jalan Nasional VIII Surabaya. Faktor - faktor pemahaman dari Pejabat Pembuat Komitmen (PPK) sebagai pengguna jasa menempatkan pemahaman dalam hukum kontrak sebagi faktor yang dominan dengan bobot (0.195), sedangkan penyedia jasa/ kontraktor menempatkan kemampuan dalam memahami hukum kontrak sebagi faktor yang dominan dengan bobot $(0.206)$.
\end{abstract}

Kata kunci : Kontraktor, Pejabat Pembuat Komitmen, Long Segment, Analitycal Hierarchy Process, Fuzzy Mamdani

\section{PENDAHULUAN}

Pemeliharaan jalan merupakan kegiatan penanganan jalan berupa pencegahan, perawatan, dan perbaikan yang diperlukan untuk mempertahankan kondisi jalan agar tetap berfungsi secara optimal sehingga umur rencana yang ditetapkan dapat tercapai. (Peraturan Menteri PU Nomor 13/PRT /M/2011).

Long segment merupakan kegiatan preservasi jalan dalam batasan satu panjang segmen yang menerus (bisa lebih dari satu ruas) yang dilaksanakan dengan tujuan untuk mendapatkan kondisi jalan yang seragam yaitu jalan mantap dan standar sepanjang segmen. Penerapan long segment sudah di mulai pada tahun anggaran 2016 dengan menggunakan acuan/ standar dokumen pengadaan pekerjaan preservasi jalan untuk pemaketan secara long segment sesuai dengan Surat Edaran Direktur Jenderal Bina Marga No.09/SE/Db/2015.

Penerapan kontrak berbasis long segment yang dinilai baru untuk penguna jasa dan kontraktor, maka di butuhkan pemahaman mengenai sistem kontrak tersebut. Para pihak mengalami kesulitan untuk menerapkan standar - standar yang sudah di tentukan serta pemahaman lingkup pekerjaan yang dilaksanakan, sehingga menyebabkan pelaksanaan pekerjaan berbasis long segment tidak efektif terlaksana dengan baik hingga saat ini 


\section{NAROTAMA JURNAL TEKNIK SIPIL \\ e-ISSN: $2460-3430$ \\ VOLUME 3 NOMOR 2 NOVEMBER 2019}

Tujuan penelitian ini adalah: (1) menganalisis Faktor dominan apa saja yang mempengaruhi tingkat pemahaman dalam kontrak berbasis long segment. Hasil yang diperoleh dapat digunakan sebagai bahan masukan untuk Kementerian Pekerjaan Umum dan Perumahan Rakyat, khususnya Direktorat Preservasi Jalan dalam evaluasi kebijakan long segment preservasi jalan nasional.

\section{METODE PENELITIAN}

Penelitian ini menggunakan metode metode Analitycal Hierarchy Process (AHP) untuk memecahkan rumusan masalah.Analytic Hierarchy Process (AHP) dapat diterima sebagai model pengambilan keputusan yang bersifat multikriteria, dalam memformulasikan prosedur pengambilan keputusan. Disamping itu, AHP juga menggunakan prinsip-prinsip eigenvector dan eigenvalue dalam proses pembobotan (saaty, 1990) . Dalam penelitian dilakukan dengan melibatkan responden yang merupakan pihak - pihak yang melaksanakan pelaksanaan pekerjaan kontruksi preservasi jalan berbasis kontrak long segment pada Balai Besar Pelaksanaan Jalan Nasional VIII Surabaya. Obyek penelitian adalah penguna jasa/ Pejabat Pembuat Komitmen (PPK) dan penyedia jasa/ kontraktor yang menangani jalan nasional pada Balai Besar Pelaksanaan Jalan Nasional VIII Surabaya. Responden diminta memberikan nilai bobot terhadap faktor yang sudah di susun sesuai dengan ketentuan metode. Sementara itu, sampel yang diperoleh sebanyak 30 responden, terdiri atas 15 responden penguna jasa/ Pejabat Pembuat Komitmen (PPK), 15 responden penyedia jasa/ kontraktor.Tahap-tahap atau prosedur AHP (Rochmasari, 2010), meliputi hal-hal sebagai berikut :

1. Mendefenisikan struktur hierarki masalah.

2. Penilaian kriteria dan alternatif dengan melakukan perbandingan berpasangan.

Tabel 1. Skala penilaian perbandingan berpasangan

\begin{tabular}{c|c}
$\begin{array}{c}\text { Intensitas } \\
\text { kepentingan }\end{array}$ & \multicolumn{1}{c}{ Definisi } \\
\hline 1 & Kedua elemen sama penting \\
\hline 3 & Elemen yang satu sedikit lebih penting daripada elemen yang lainnya \\
\hline 5 & Elemen yang satu lebih penting daripada elemen yang lainnya \\
\hline 7 & Satu elemen lebih mutlak penting daripada elemen yang lainnya \\
\hline 9 & Satu elemen mutlak penting daripada elemen yang lainnya \\
\hline $2,4,6,8$ & Nilai-nilai antara dua nilai pertimbangan yang berdekatan \\
\hline
\end{tabular}

\section{ANALISA DAN PEMABAHASAN}

Dalam peneleitian ini pengolahan data dan perihitungan mengunakan software Expert Choice 11. Expert Choise adalah suatu sistem yang digunakan untuk melakukan analisa, sistematis, dan pertimbangan (justifikasi) dari sebuah evaluasi keputusan yang kompleks. Dengan menggunakan Expert Choice, maka tidak ada lagi metode cobacoba dalam proses pengambilan keputusan. Dengan didasari oleh Analitycal Hierarchy Process (AHP), penggunaan hirarki dalam Expert Choice bertujuan untuk mengorganisir perkiraan dan intuisi dalam suatu bentuk logis. Pendekatan secara hierarki ini memungkinkan pengambil keputusan untuk menganalisa seluruh pilihan untuk pengambilan keputusan yang efektif.

Tabel 2. Struktur Hirarki Tingkat Pemahaman Pelaksanaan Proyek Long segment 
NAROTAMA JURNAL TEKNIK SIPIL

e-ISSN: 2460-3430

VOLUME 3 NOMOR 2 NOVEMBER 2019

\begin{tabular}{|c|c|c|c|}
\hline \multicolumn{4}{|c|}{ PENYEDIA JASA (PPK) } \\
\hline & KORELASI & & \\
\hline 1. Pemahamandalamhukumkontrak & (b,c,d,e,f,g,h,i) & a) & Pemahamandalamhukumkontrak \\
\hline 2. Pemahamankontraklong segment & $(\mathrm{c}, \mathrm{d}, \mathrm{e}, \mathrm{f}, \mathrm{g}, \mathrm{h}, \mathrm{i})$ & b) & Pemahamankontraklong segment \\
\hline $\begin{array}{l}\text { 3. Pemahaman tentang Indikator Kinerja } \\
\text { Jalan }\end{array}$ & $(d, e, f, g, h, i)$ & c) & $\begin{array}{l}\text { Pemahaman tentang Indikator Kinerja } \\
\text { Jalan }\end{array}$ \\
\hline 4. Pemahaman tentang Lingkup & $(e, f, g, h, i)$ & d) & Pemahaman tentang Lingkup \\
\hline $\begin{array}{l}\text { Pekerjaan Proyek Long segment } \\
\text { 5. Pemahaman tentang denda proyek } \\
\text { jalan dengan sistem long segment }\end{array}$ & $(f, g, h, i)$ & e) & $\begin{array}{l}\text { Pekerjaan Proyek Long segment } \\
\text { Pemahaman tentang denda proyek } \\
\text { jalan dengan sistem long segment }\end{array}$ \\
\hline $\begin{array}{l}\text { 6. Pemahaman dalam melaksanakan } \\
\text { kontrak }\end{array}$ & $(\mathrm{g}, \mathrm{h}, \mathrm{i})$ & f) & $\begin{array}{l}\text { Pemahaman dalam melaksanakan } \\
\text { kontrak }\end{array}$ \\
\hline 7. Pemahaman dalam membuat Berita & $(h, \mathrm{i})$ & g) & Pemahaman dalam \\
\hline $\begin{array}{l}\text { Acara Penyerahan Pertama }(\mathrm{PHO}) \\
\text { kepada PA/KPA }\end{array}$ & & & $\begin{array}{l}\text { Acara Penyerahan Pertama }(\mathrm{PHO}) \\
\text { kepada PA/KPA }\end{array}$ \\
\hline $\begin{array}{l}\text { 8. Pemahaman waktu pelaksanaan } \\
\text { kontrak }\end{array}$ & (i) & h) & $\begin{array}{l}\text { Pemahaman waktu pelaksanaan } \\
\text { kontrak }\end{array}$ \\
\hline $\begin{array}{l}\text { 9. Pemahaman dalam pemenuhan } \\
\text { indikator kinerja }\end{array}$ & & i) & $\begin{array}{l}\text { Pemahaman dalam } \\
\text { indikator kinerja }\end{array}$ \\
\hline
\end{tabular}

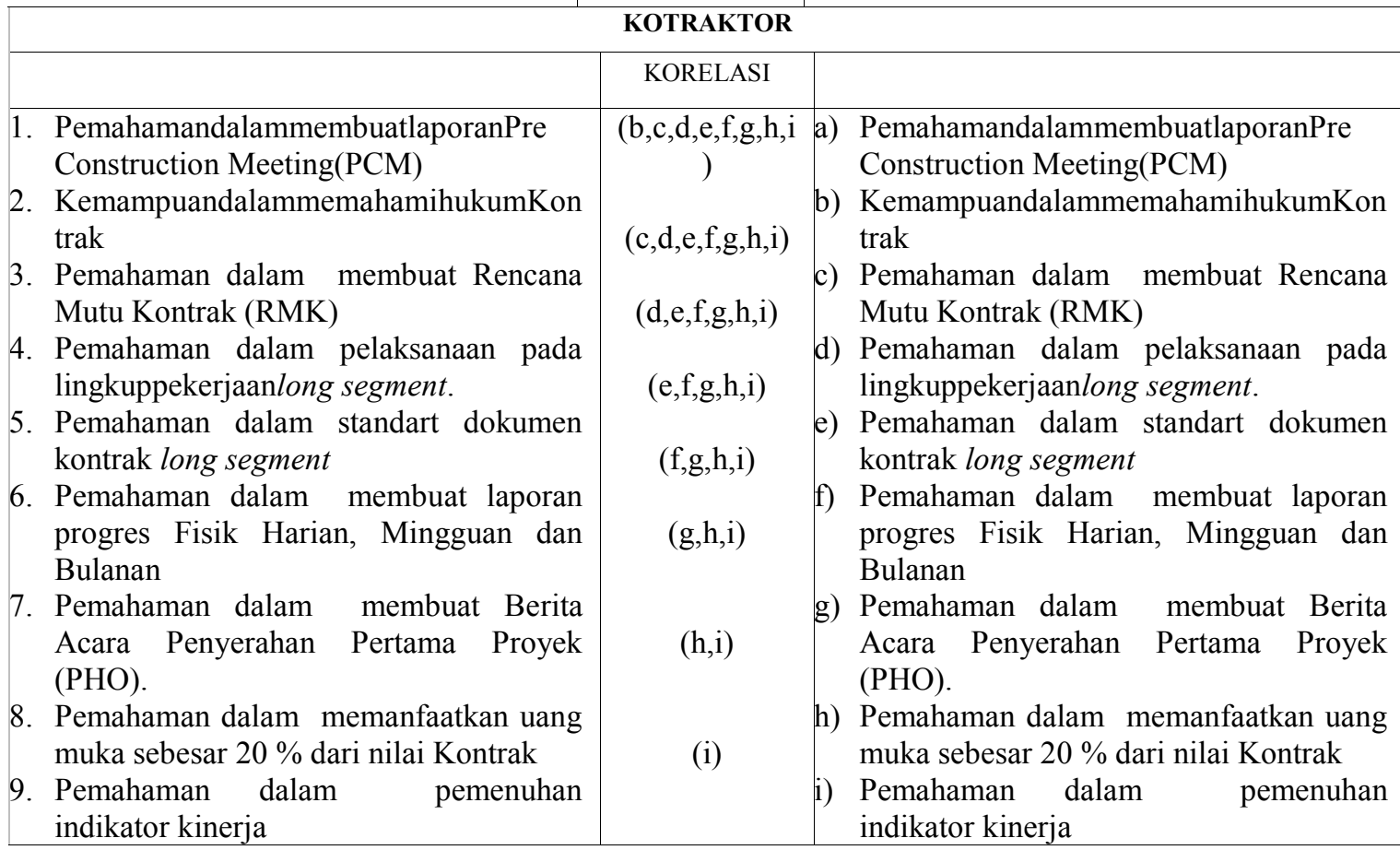

\section{a. Proses Analisa}

Pengunaan software Expert Choice 11 dibutuhkan data yang di dapat dari pengisian kuisioner yang sudah di lakukan oleh responden dalam penelitian ini dalan di lakukan penginputan kedalam software seperti gambar di bawah ini. 


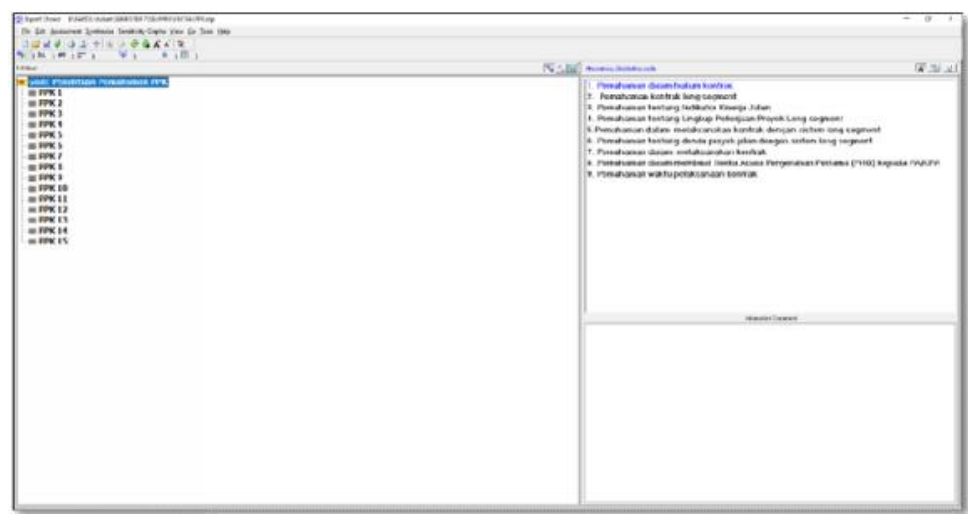

Gambar 1. Pengisian Goal dan Faktor

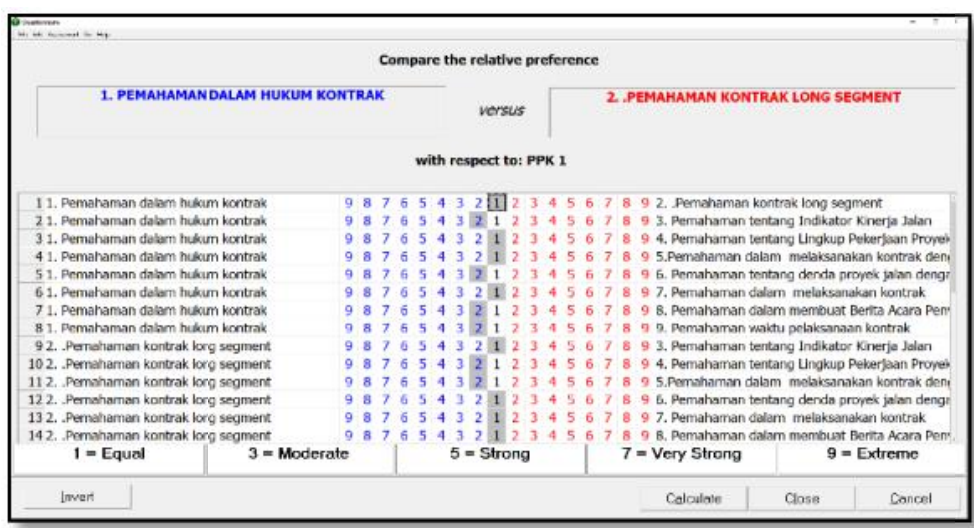

Gambar 2. Pengisian Kuisioner

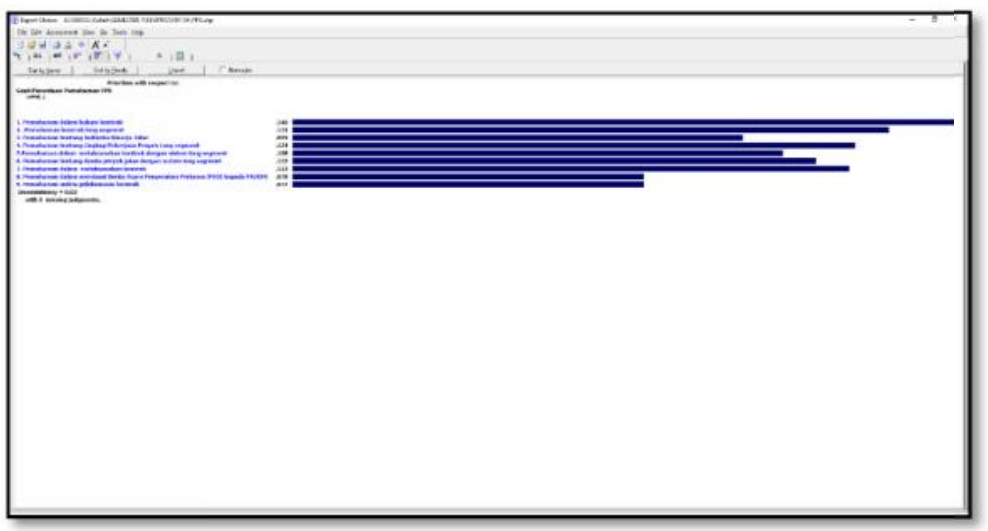

Gambar 3.Hasil Kalkulasi

Pengisian dilakukan sesuai dengan hasil isian kuisioner yang di isi oleh responden. Syarat yang harus di penuhi adalah dari hasil kalkulasi inconsistency harus $<0.1$, apabila hasil kalkulasi dari data yang sudah di masukan mendapatakan inconsistency $>$ 0.1, maka akan di lakukan pengambilan hasil keputusan ulang oleh responden yang sama atau yang berbeda.Keluaran yang dihasilkan dalam software ini adalah nilai bobot dari masing - masing faktor yang sudah di berikan nilai. Selain itu, dengan software ini dapat mengetahui faktor - faktor yang mempunyai nilai tertinggi dan terendah seperti tabel di bawah ini: 


\section{NAROTAMA JURNAL TEKNIK SIPIL \\ e-ISSN: 2460-3430 \\ VOLUME 3 NOMOR 2 NOVEMBER 2019}

Tabel 3. Tabel Kalkulasi PPK

\begin{tabular}{clc}
\hline \multirow{2}{*}{ PPK } & \multicolumn{1}{c}{ Pemahaman PPK } & \multirow{2}{c}{ Faktor 1 } \\
\cline { 3 - 4 } & \multicolumn{1}{c}{ Bobot } \\
\hline 2 & 1. Pemahaman dalam hukum kontrak & 0.195 \\
\hline 3 & 2. Pemahaman dalam hukum kontrak & 0.191 \\
\hline 4 & 1. Pemahamaman dalam hukum kontrak & 0.186 \\
\hline 5 & 3. Pemahaman tentang Indikator Kinerja Jalan & 0.181 \\
\hline 6 & 2. Pemahaman kontrak long segment & 0.175 \\
\hline 7 & 4. Pemahaman tentang Lingkup Pekerjaan Proyek Long segment & 0.152 \\
\hline 8 & 5.Pemahaman dalam melaksanakan kontrak dengan sistem long segment & 0.148 \\
\hline 9 & 1. Pemahaman dalam hukum kontrak & 0.143 \\
\hline 10 & 1. Pemahaman dalam hukum kontrak & 0.142 \\
\hline 11 & 2. Pemahaman kontrak long segment & 0.141 \\
\hline 12 & 1. Pemahaman dalam hukum kontrak & 0.139 \\
\hline 13 & 3. Pemahaman tentang Indikator Kinerja Jalan & 0.138 \\
\hline 14 & 1. Pemahaman dalam hukum kontrak & 0.136 \\
\hline 15 & 3. Pemahaman tentang Indikator Kinerja Jalan & 0.136 \\
\hline
\end{tabular}

Dari faktor - faktor yang diberikan untuk responden dalam tingkat pemahaman Pejabat Pembuat Komitmen (PPK) sebagai pengguna jasa pekerjaan preservasi jalan berbasis kontrak long segment pada Balai Besar Pelaksanaan Jalan Nasional VIII dapat disimpulkan hasilnya.

Tabel 4. Tabel Kalkulasi Kontraktor

\begin{tabular}{clc}
\hline \multirow{2}{*}{ No } & \multicolumn{1}{c}{ Pemahaman Kontraktor } & Bobot \\
\cline { 3 - 4 } & & \multicolumn{1}{c}{ Faktor 2 } \\
\hline 2 & 2.Kemampuan dalam memahami hukum Kontrak & 0.206 \\
\hline 3 & 2.Kemampuan dalam memahami hukum Kontrak & 0.188 \\
\hline 4 & 3.Pemahaman dalam membuat Rencana Mutu Kontrak (RMK) & 0.187 \\
\hline 5 & 9.Pemahaman dalam pemenuhan indikator kinerja & 0.182 \\
\hline 6 & 9.Pemahaman dalam pemenuhan indikator kinerja & 0.182 \\
\hline 7 & 2.Kemampuan dalam memahami hukum Kontrak & 0.18 \\
\hline 8 & 9.Pemahaman dalam pemenuhan indikator kinerja & 0.18 \\
\hline 9 & 2.Kemampuan dalam memahami hukum Kontrak & 0.179 \\
\hline 10 & 5.Pemahaman dalam standart dokumen kontrak long segment & 0.179 \\
\hline 11 & 5.Pemahaman dalam standart dokumen kontrak long segment & 0.178 \\
\hline 12 & 2.Kemampuan dalam memahami hukum Kontrak & 0.177 \\
\hline 13 & 2.Kemampuan dalam memahami hukum Kontrak & 0.168 \\
\hline 14 & 5.Pemahaman dalam standart dokumen kontrak long segment & 0.165 \\
\hline 15 & 4.Pemahaman dalam pelaksanaan pada lingkup pekerjaan long segment. & 0.162 \\
\hline & & 0.154 \\
\hline
\end{tabular}




\section{NAROTAMA JURNAL TEKNIK SIPIL \\ e-ISSN: $2460-3430$ \\ VOLUME 3 NOMOR 2 NOVEMBER 2019}

\section{KESIMPULAN}

Kesimpulan yang dapat diambil dari penelitian ini adalah sebagai berikut:

1. Dari hasil perhingan menggunakan software expert choice 11 maka, faktor - faktor dominan yang mempengaruhi tingkat pemahaman para pengguna jasa, kontraktor yang terkait dalam pekerjaan preservasi jalan besbasis kontrak long segment.

a. Faktor - faktor dominan disertai bobot yang mempengaruhi tingkat pemahaman Pejabat Pembuat Komitmen (PPK) dalam melaksanakan pekerjaan preservasi jalan berbasis kontrak long segment adalah:

- Pemahaman dalam hukum kontrak (0.195)

- Pemahaman kontrak long segment (0.186)

- Pemahaman tentang Indikator Kinerja Jalan (0.175)

- Pemahaman tentang Lingkup Pekerjaan Proyek Long segment (0.148)

- Pemahaman dalam melaksanakan kontrak (0.143)

b. Dari hasil perhingan menggunakan software expert choice 11 maka, faktor faktor dominan disertai bobot yang mempengaruhi tingkat pemahaman penyedia jasa/ kontraktor dalam melaksanakan pekerjaan preservasi jalan berbasis kontrak long segment adalah:

- Kemampuan dalam memahami hukum Kontrak (0.206)

- Pemahaman dalam membuat Rencana Mutu Kontrak (RMK) (0.182)

- Pemahaman dalam pemenuhan indikator kinerja (0.182)

- Pemahaman dalam standart dokumen kontrak long segment (0.178)

- Pemahaman dalam pelaksanaan pada lingkup pekerjaan long segment (0.154)

\section{DAFTAR PUSTAKA}

1. Andri Budilukito. 2016. Kesiapan Kontraktor Terhadap Kebijakan Preservasi Jalan Nasional di Sumatera Selatan. Jurnal HPJI Vol. 2 No. 2 Juli 2016

2. Derrick, J.-Z. T., \& F.E., M. G. 2011. Critical Succes Factor for Malaysian Contractor Project using AHP. EPPM, Singapore, 20-21 September 2011.

3. Kusumadewi, Sri dan Hari Purnomo. 2010. Aplikasi Logika Fuzzy Untuk Pendukung Keputusan. Yogyakarta: Graha Ilmu

4. Mohammad Ari Subadra. 2018. Analisis Tingkat Kesiapan Dan Pemahaman Pada Proyek Jalan Nasional Dengan Sistem Long segment Menggunakan Metode Analytical Hierarchy Process (AHP). Tesis Megister Teknik Sipil Universitas 17 Agustus.

5. Muhamad Abduh. 2015. Model Penilaian Kewajaran Harga Penawaran Kontraktor dengan Sistem Evaluasi Nilai. Vol. 12 No. 3 Juli 2005

6. Saaty, T.L. 1980. The Analytic Hierarchy Process. McGraw-Hill. New York.

7. Saaty, T.L. 2004. Decision making - the Analytic Hierarchy and Network Processes (AHP/ANP). Journal of Systems Science and Systems Engineering. March 2004, Volume 13, Issue 1, pp 1-35

8. Saaty, T.L. 2008. Decision making with the analytic hierarchy process . Int. J. Services Sciences, Vol. 1, No. 1, 2008 